\title{
Thermodynamic Analysis, Advanced Non-Linear Dynamic Simulation and Multi- Criteria Optimization of a 100 MW Parabolic Trough Solar Steam Power Plant
}

\author{
E. Mofidipour ${ }^{1}$, M. Babaelahi ${ }^{1, *}$, A. Arabkoohsar ${ }^{2}$ \\ ${ }^{1}$ Department of Mechanical Engineering, University of Qom, Iran \\ ${ }^{2}$ Department of Energy Technology, Aalborg University, Denmark \\ E-mail:m.babaelahi@qom.ac.ir,mbabaelahi@gmail.com
}

Received 17 February 2021, Revised 15 April 2021, Accepted 19 June 2021

\begin{abstract}
Thermodynamic analyses of concentrating solar power plants and optimizing these cycles relying on the energetic and exergetic optimal efficiencies are quite common. However, it is found that just considering the efficiency of the system for performance optimization and neglecting the adverse effects of the plant's wrong operation timings, which is a function of the solar working fluid flow rate, can easily give misleading optimization results. This study's primary goal is to find the optimal operating point of the cycle in terms of the thermodynamic efficiencies considering the system's operating time. Thus, the Sliding Mode Control (SMC) approach is employed to provide a proper mass flow rate for the working fluid from the solar collector field to achieve a precise output temperature from the collectors in different operating conditions. Multi-objective optimization is performed using the Particle Swarm Optimization (PSO) algorithm. The results of power block sensitivity analysis indicate that a $70^{\circ} \mathrm{C}$ increase in the solar collector outlet temperature remarkably enhances electricity generation and exergetic efficiency by 67 and $48 \%$. The twoobjective optimization shows $22.01 \%, 2.10 \%$, and $5.46 \%$ enhancement in response time, thermal efficiency, and exergetic efficiency, and the three-objective optimization reveals $3.68 \%$ and $3.74 \%$ improvement in efficiency (thermal and exergetic), respectively.
\end{abstract}

Keywords: Dynamic; exergy; energy; thermodynamic; solar; power plant.

\section{Introduction}

One of the critical issues that have great significance in assessing and optimizing powerplants, particularly in renewable-based energy systems, is achieving a scheme in which all the improvable aspects are considered. Unfortunately, in the vast range of recent literature, only one aspect of power generation systems performance has been considered, and the other elements have not been reviewed [1]. Therefore, this paper presents a novel approach in which various aspects of the power generation system are examined and evaluated simultaneously. In energy systems, there are various approaches, of which some are discussed in this section.

There is a growing concern about the environmental degradation effects of fossil fuels nowadays. a widely accepted notion that renewable-based power plants will be of utmost importance in the future due to the inertia services they offer for the grid frequency balances. In the $21 \mathrm{st}$ century, Spain is the most enthusiastic nation about utilizing solar-driven power plants. Other nations such as India, South Africa, and the US are also shown their interest in the fast deployment of more renewable-based cycles. It should be noted that Spain's solar collector field's capacity is approximately $2300 \mathrm{GW}$ by 2016 [2].

Before development, however, all useful indexes of the renewable-based power plants should be scrutinized. The performance of these systems can witness a radical change by considering some significant factors. In this article, simultaneous energy and exergy efficiency, system dynamic behavior in a solar-driven Organic Rankine cycle (ORC) has been attempted. In most literature, researchers mostly assessed several features of these powerplants and proposed proposals for enhancing these plants' performance, and thermodynamic and economic assessment. Regarding thermodynamic analysis, Sachdeva et al. [3] assessed the energy efficiency and net power output of a triple integrated cycle (Rankine, Brayton, and Organic Rankine Cycle) and second law efficiency for carbon-free power.

Thermodynamic investigation and concurrent optimization of an ORC coupled with a solar system have been conducted by Yang et al. [4] . They proposed a novel operating point of a solar system for a stable solar power system output. Moreover, they enhanced the maximum efficiency up to $17.9 \%$ with recuperative ORC utilizing toluene. A broad assessment of a solar-powered steam-auto thermal hybrid power plant reforming for ammonia and power production has been conducted by Eshagh et al. [5]. Their system produced adequate power to meet the demands of supply like a final commodity. They proposed an indicator that provided information on the system's performance based on energy and exergy efficiency.

A new cogeneration ORC and coal-fired power plant have been investigated by Zhang et al. [6]. They enhanced net power output and heating capacity simultaneously by utilizing a new method based on the cycle's energy and exergy performance. Adibhatla et al. [7] assessed the exergy and thermo-economic assessment of a solar-powered sub- 
critical power plant aided by feed water heating. Solar field and steam generator exergetic efficiencies in their study were about $21.10 \%$ and $43.48 \%$, respectively. A thermodynamic analysis of a solar hybrid coal-based power cycle has been conducted by Xu et al. [8]. In their study, A new solar-coal hybridization power cycle emission-free was proposed, and the solar system had a more contribution to power generation in the end than their last scheme.

Cojocaru et al. [9] studied an optimal operation strategy for solar thermal cycles with thermal energy storage units based on Spain's market conditions. They concluded that such an optimal operation plan could reduce the system's loss, which will result in an increased lifetime and lower maintenance costs. Rashid et al. [10] presented a thermoeconomic analysis of different approaches to hybridizing solar thermal power plants with conventional power cycles. They concluded that solar share and thermal efficiency of the power production from solar energy could increase by 70 and $78 \%$, respectively. Khajepour and Ameri [11] compared the technical performance of three different schemes of Fresnel solar fields coupled with a conventional steam power cycle. And concluded that the use of thermal storage units in such plants could not be economically advised but only if natural gas price is extravagant. Tapaches et al. [12] made a technoeconomic assessment and optimization of renewable power generation systems with thermal storage units. They also concluded that the number of charging-discharging rounds of the storage unit depends on several parameters, such as the season and location. The fact that subsidies are still required to make such power plants economically feasible.

All the studies mentioned above were considered the thermodynamic or economic performances of power plants. However, other features of renewable-based power plants could cause a radical change in these systems' performance [13]. The dynamic behavior of these systems is of the utmost importance due to several reasons. First and foremost, it has a profound impact on the thermodynamic behavior of parabolic trough collector (PTC) systems. Moreover, it can drastically lessen system efficacy by reducing the operating time and making the system agile. There is a multitude number of studies concerning the dynamic simulation of solar-driven power plants. Simultaneous thermodynamic and dynamic analysis of these systems seems to be largely ignored in the past literature.

A mathematical model for dynamic simulation of a solardriven Organic Rankin Cycle (ORC) with thermal energy storage unit has been proposed by Sung et al. [14]. The effect of clearness index and probability persistence were considered in their model. The proposed model has shown more accurate results compared with the previous models. Wisam et al. [15] dynamically assessed a 50MW parabolic trough steam power plant in Spain during clear days and slightly cloudy periods. Advanced control circuits such as drum level, economizer water bypass, attemperator, and steam bypass controller were also considered in their simulation. Simultaneous analysis between dynamic behavior and economic performance of a concentrated solar power plant (CSP) retrofitted energy storage unit has been conducted by Rashidi et al. [16]. They simulated a PTCnatural gas plant and provided an elaborated dynamic model with a promising control technique. A triple pressure integrated powerplant with PTCs has been assessed by Calise et al. [17]. A new control approach was implemented to delimit steam turbine off-design operation and the technoeconomic analysis of this power plant. In further research, Li et al. [18] evaluated a solar-powered power plant's dynamic behavior. They utilized real meteorological data for plant simulation, and their system was able to operate even after sunset. Abas et al. [19] utilized TRNSYS ${ }$ software for simulating a solar water heating system using supercritical $\mathrm{CO} 2$ as a mediating fluid in certain conditions. They achieved a high system performance as a specific solar fraction and operating duration. Gallego et al. [20] evaluated a Fresnel collector field, and they utilized the gainscheduling model predictive control for their control purpose. They realized that advanced control strategies are vitally crucial in solar collector systems in certain circumstances, and linear control tactics may not function properly. In many studies, researchers utilized a distributed state-state model of a CSP plant for control applications such as Costo et al. [21]. They put forward approaches that were illuminated phase changes in space and time for the solar field. Sliding mode predictive control has been utilized in an ultra-supercritical power plant with massive uncertainties and input constraints by Tian et al. [22]. They proposed a control technique based on this non-linear control method and addressed these fluctuations and constraints in their design. A dynamic analysis of a linear parabolic through solar power plant retrofitted with the latent thermal energy storage (LTES) system was conducted by Mosleh et al. [23]. They used PCMs to assess the impact of LTES in the whole system and eventually they concluded that the solar fraction of their proposed PCM increases as the collector's thermal loss declines. Various control techniques for an ORC system using zeotropic as a working fluid have been proposed by Chen et al. [24]. They investigated dynamic characteristics with external controllable conditions and different evaporation stages of their system.

The current paper attempts to present a method that simultaneously studies the efficiency and agility (against load changes aspects) of power generation systems. Unfortunately, in the past research, only one or two aspects, as mentioned above, have been considered for the analysis of power generation systems, and the other aspects have not been considered. This procedure caused the system to be poorly designed and optimized. Therefore, this research proposes a scheme in which all the affecting thermodynamic and dynamic parameters decision variables for the optimization problem. Thermodynamic parameters refer to energy and energy efficiency, and dynamic behavior is evaluated via system response time. System response time is negatively affected by external\&internal uncertainties and fluctuations, which force the designer to develop a control system for better operation. The highly robust non-linear control approach (SMC) is employed in this research.

It is essential to have a new approach for analyzing the power generation systems that cover all the significant aspects. This paper presents a novel approach in which the principles of thermodynamic efficiency analysis and control system agility are evaluated simultaneously based on decision variables. A steam power generation cycle using solar energy as a heat source is selected as the case study to achieve this goal. In the first step of this article, energy and exergy analyses are performed based upon the first and second laws of thermodynamic to evaluate cycle performance. The next step is precision modeling of the solar system, and the suitable control system is designed for the solar system. For the control system, the robust non-linear control method so-called SMC is selected. The above steps' output is the thermodynamic efficiency (energy and exergy) 
and the settling time of the control system, all of which depend on performance variables (decision variables). Finally, to achieve the optimal design that combines all aspects of the system performance, multi-objective optimization (using MPSO) has been used to maximize efficiency and minimize the control system's response time. A brief explanation of this article achievement:

- Simultaneous thermodynamic and dynamic assessment of a solar-powered steam power plant

- Utilizing a non-linear SMC algorithm for solar system outlet temperature regulation

- Simultaneous energy and energy investigation of the solar-powered steam power plant

- Evaluation of nominal operating point of the cycle in terms of thermodynamic and dynamic performance

\section{Problem Definition and Method}

To improve PTC systems, they have to be equipped with control systems. Many researchers have developed many control algorithms to improve the efficacy of these systems recently. However, due to the severe external and internal fluctuations that these systems might be exposed to, the demand for more promising control techniques increases. In renewable energy systems, the primary purpose is to maintain the outlet temperature of heat transfer fluid (HTF) flowing into the absorber of these systems at a fixed level. Whereas, external fluctuations, load variations, changing daylight levels, the position of clouds during days, and the temperature of HTF at the beginning of the process are the significant reasons that deter the system from functioning properly. Control systems are an excellent help to overcome these fluctuations by manipulating the HTF's mass flow rate during the system operating time, which helps the system meet its flow demand. For this purpose, in this article, a non- linear control (SMC) approach is utilized. Sliding mode control is a robust control approach that utilizes a discontinuous control approach to change the non-linear system dynamics and forces the system to slide around systems' normal behavior. For more information, see the reference [25].

After developing an advanced control system and identifying the system response time to the desired reference temperature, this duration needs to be improved. For this, two/three objective optimization techniques are employed. Along with dynamic behavior (response time), thermodynamic parameters also need to be considered in multi-objective optimizations such as, thermal and exergetic efficiencies. Therefore, the power plant can function properly in all aspects, with less time and mass flow rate.

\subsection{Parabolic trough solar power plant}

The schematic of a solar-powered thermal power plant is illustrated in Figure 1 [26]. The plant size is about $100 \mathrm{MW}$. The simulation of a power plant requires $113 \mathrm{~kg} / \mathrm{s}$ of steam through a solar system. The boiler stream in the output has 100 bar pressure and $371^{\circ} \mathrm{C}$ temperature, while there is a reheat line at 16.5 bar and $370^{\circ} \mathrm{C}$, which contributes to the high steam temperature. According to the figure, the PTC system heats the HTF (Therminol VP1), then splitting the stream in the further stage. The first stream flows through the superheater, evaporator, and the preheater to produce high pressure/temperature steam before entering the steam turbine. Simultaneously, the second stream is passed through the pre-heater to heat low-temperature steam turbine and, consequently, increase the plant efficiency._Then, the cold HTF streams are mixed and re-circulated back into the PTC field for repeating the process.

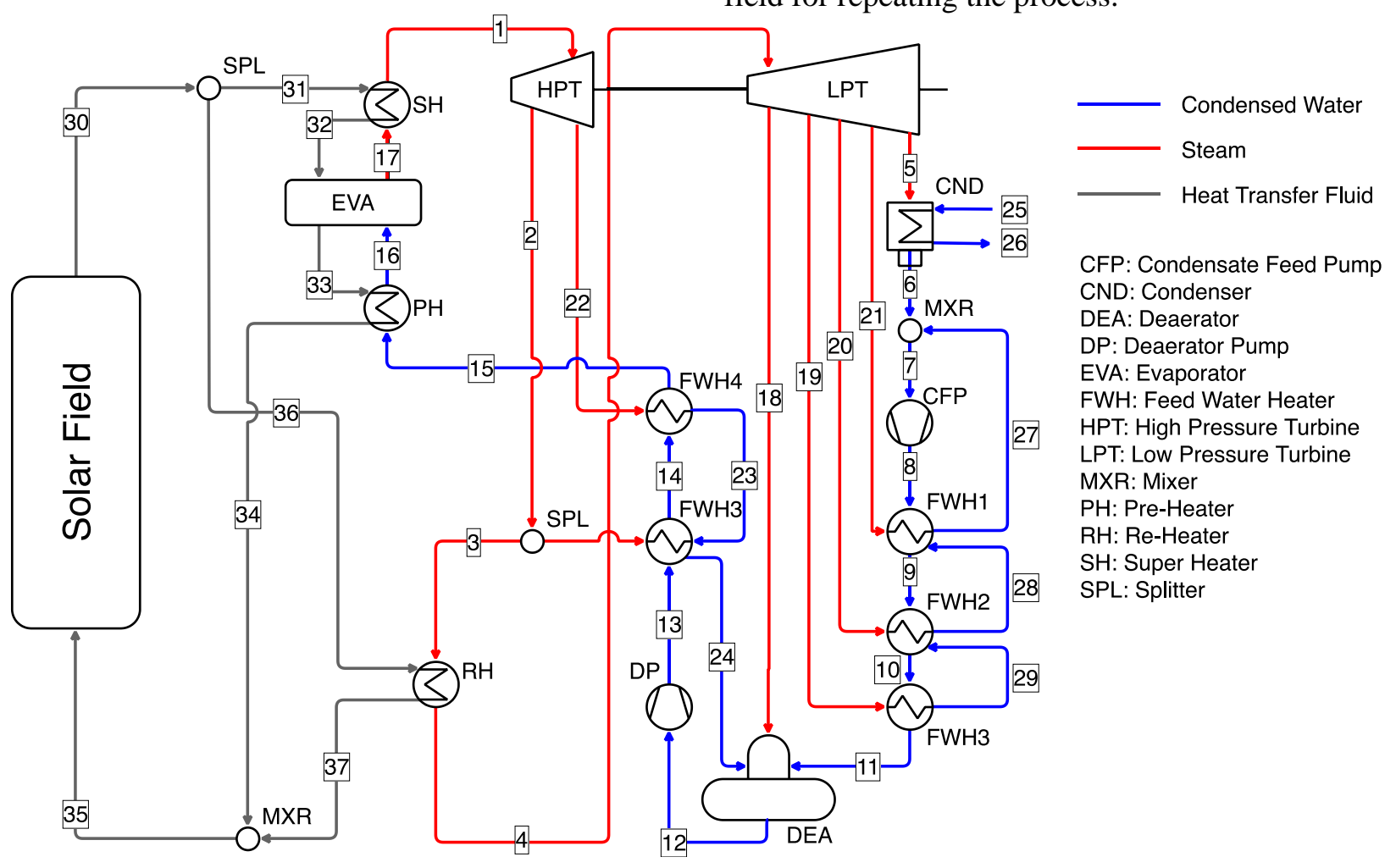

Figure 1. Schematic view of the considered solar-driven Rankine cycle. 
The cycle's operational and geometrical variables are expressed in the following Table 1. This solar power plant (illustrated in Figure 1 and specified in Table 1) has two rows of collectors, with approximately 132 meters' total parabolic collectors' length.

Table 1. Power plant process inputs and assumptions.

\begin{tabular}{|c|c|c|c|}
\hline & Parameter & Symbol & Value \\
\hline & $\begin{array}{l}\text { Feedwater Heaters Terminal } \\
\text { Temperature Difference }\end{array}$ & TTD & $5^{\circ} \mathrm{C}$ \\
\hline $\bar{\Xi}$ & Isentropic Efficiency (Pumps) & $\eta_{\text {isp }}$ & $80 \%$ \\
\hline تี & Isentropic Efficiency (Turbines) & $\eta_{\text {ist }}$ & $88 \%$ \\
\hline$\ddot{z}$ & Mechanical Efficiency (Pumps) & $\eta_{\mathrm{mp}}$ & $99 \%$ \\
\hline 苞 & Mechanical Efficiency (Turbines) & $\eta_{\mathrm{mT}}$ & $99 \%$ \\
\hline & Electrical Generator Efficiency & $\eta_{\text {ge }}$ & $98 \%$ \\
\hline & Width Of The Collector & $\mathrm{w}$ & $5 \mathrm{~m}$ \\
\hline $\bar{\Xi}$ & Parabolic Rim Angle & $\phi_{\text {rim }}$ & $80^{\circ}$ \\
\hline & Number Of Parallel Sections & $\mathrm{n}_{\mathrm{ps}}$ & 2 \\
\hline
\end{tabular}

Environmental circumstances and solar irradiance for a four-hour duration between 11:00 am to 3:00 pm is illustrated in Figure 2. The data has been collected in a summer day in Shiraz, Iran and has been considered various features affecting ambient temperature simultaniously [27].

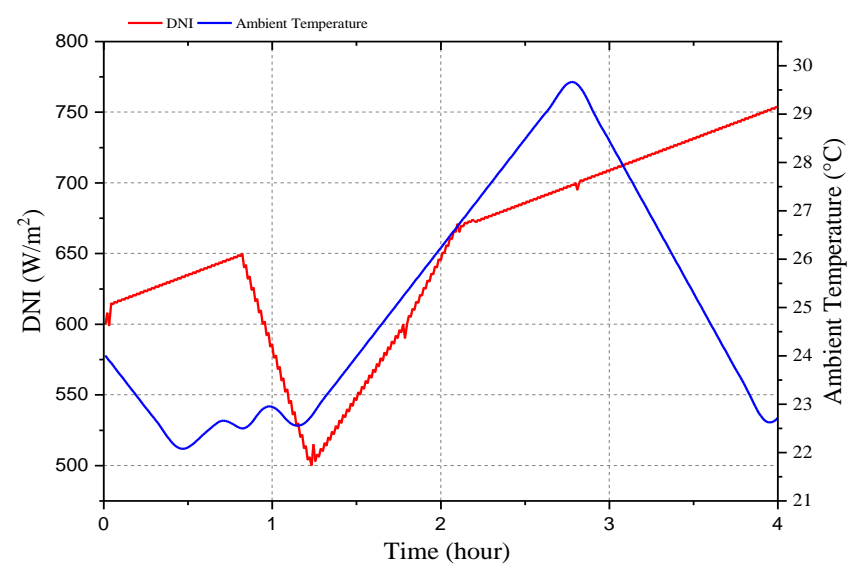

Figure 2. Environmental circumstances (Radiation and ambient temperature).

\subsection{Control system development}

SMC strategy: In SMC, the system states are taken to a level called the "sliding surface" in the state space phase. When the modes reach the sliding surface, the sliding mode control keeps the modes close to and adjacent to the sliding surface. This approach is a two-part control method. In the first part, a sliding surface is defined to meet the design specifications' sliding motion. In the second part, the control rule is selected to absorb the switching level of the system mode [28].

Sliding mode control has two main advantages. The first advantage is that the system's optimal dynamic behavior can be achieved by selecting the appropriate sliding function. The second advantage is that the system's closed-loop response has no sensitivity to uncertainties (model parameters, perturbations, and nonlinearity). Consequently, from a practical point of view, non-linear processes in the presence of model perturbations and uncertainties can be controlled.

\section{Modeling}

In this section, a mathematical model is provided for the case study power plant's thermodynamic analysis and the applied SMC for the solar field.

\subsection{Thermodynamic modeling}

The thermodynamics-first law can be used to specify the therodynamic features of the plant. Apart from thermodynamics-second law's ability to confirm the energy analysis in discovering the sources of irreversibilities, it can contribute to practical potentials for the improvement of the performance of the cycle. The general energy balance equation for each specific system control volumes could be written as follows [27]:

$$
\begin{gathered}
\dot{Q}_{c v}-\dot{W}_{c v}+\sum \dot{m}_{i}\left(h_{i}+\frac{V_{i}^{2}}{2}+\mathrm{g} z_{i}\right)+ \\
\sum \dot{m}_{i}\left(h_{e}+\frac{V_{e}^{2}}{2}+\mathrm{gz}_{\mathrm{e}}\right)=0
\end{gathered}
$$

Where the terms in the brackets account for the specific energy for the incoming and outgoing streams. The terms $\dot{Q}$ and $\dot{W}$ show, respectively, for the net rates of energy transfer by heat and work.

The exergy of a fluid stream can be determined by:

$$
e x_{f}=\left(h-h^{*}\right)-\mathrm{T}_{0}\left(s-s^{*}\right)+\sum_{i=1}^{n} y_{i}\left(\mu_{i}^{*}-\mu_{i}^{0}\right)
$$

Here, $\mathrm{n}, \mathrm{y}_{\mathrm{i}}$ and $\mu_{\mathrm{i}}^{0}$ are the number, mole fraction, and the standard chemical exergy. In this research, the Ebsilon professional software database has been employed for identifying the thermodynamic properties of the fluid streams.

The exergy for the specific control volume can be presented as:

$$
\begin{aligned}
& \frac{d E_{x}}{d t}=\sum\left(1-\frac{T_{0}}{T}\right) Q+\left(W-\mathrm{P}_{0} \frac{d v}{d t}\right)+\sum \dot{m}_{i} e x_{i}-\sum \dot{m}_{e} e x_{e}- \\
& \dot{E} x_{D}
\end{aligned}
$$

The destruction of exergy, known as irreversibility, can be examined by subtracting the output exergy (so-called product exergy) of each component from its input exergy (so-called fuel exergy):

$$
\dot{E} x_{D}=\dot{E} x_{\text {fuel }}-\dot{E} x_{\text {product }}
$$

As the flow diagram (Figure 1) shows, the source of energy and exergy entering the system is the solar system. Based on this input of energy and exergy, energy and exergy efficiencies are defined as follows:

$$
\begin{aligned}
& \eta_{T}=\frac{\text { Net Turbine Work }}{\text { Input Energy }}=\frac{W_{\text {net }}}{Q_{\text {solar field }}} \\
& \varepsilon=\frac{W_{\text {net }}}{\text { Input Exergy }}=\frac{W_{\text {net }}}{E x_{30}-E x_{35}}
\end{aligned}
$$

\subsection{Dynamic Modeling}

Generally, there are two sets of the equation for PTC field modeling: distributed and lumped parameter models. The distributed parameter model has been carried out by Carmona in 1985 [28]. The presented lumped parameter equation reveals the HTF temperature varioations inside of the solar unit absorber. The absorber receives the reflected solar heat from solar panels. This equation defines in an unsteady state for control purposes mostly for regulating the solar system outlet temperature. This energy equation can be expressed as follows [28]: 
$\mathrm{C} \frac{d T}{d t}=\eta_{\mathrm{col}} \mathrm{GI}-q \rho_{c p}\left(T-T_{f_{m}}\right)-\mathrm{H}_{1}\left(T_{m}-T_{a}\right)$

Controller design: To ensure the solar collector temperature stability at the setpoint by control the mass flow rate at the PTC, the idea of controller development is mentioned. The highly depends on the system dynamic constraints, environmental circumstances, average solar irradiance, and flow rate, affecting the oil temperature. To eliminate the mathematical complexity of the proposed control approach, a step-by-step flow chart of the control scheme could be given as follows:

1. Determine the switching function $S(x, t)$ from the tracking error

2. Determine the sliding surface

3. Determine the collector estimation value

4. Utilize control law $u=\hat{b}^{-1}(\hat{u}-k \operatorname{sign}(s))$

5. Substitute the value of $\hat{u}$ to the control law

6. Determine the value for $\mathrm{k}$ and $\hat{b}^{-1}$

7. Change the signum function into a saturation function

First, by utilization of Lyapunov's theory [27], the system tracking error is defined, and is attempted tracking error converges to zero, which means here stability of the control system:

$\mathrm{e}(t)=T_{d e s}-T$

The sliding surface is considered equal to the system error according to the theory mentioned above. $\mathrm{S}=\mathrm{e}(t)$

The Lyapunov function, which expresses the system internal energy, is as follow:

$\mathrm{V}(t)=\frac{1}{2} \mathrm{e}(t)^{2}$

According to the mathematical theories, the negative derivation of this function represents how system error converges to zero:

$\dot{\mathrm{e}}(t)=\dot{T}_{\text {des }}-\dot{T}=\dot{T}_{\text {des }}$

$\frac{\eta_{\mathrm{col}} \mathrm{GI}-q \rho_{c p}\left(T-T_{f_{i n}}\right)-H_{l}\left(T_{m}-T_{a}\right)}{C}$

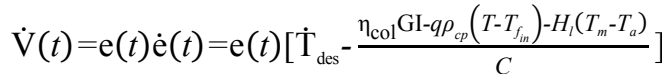

$\mathrm{f}$ and $\mathrm{b}$ is can be presented as follow:

$f=\frac{\eta_{\mathrm{col}} \mathrm{GI}-H_{l}\left(T_{m}-T_{a}\right)}{C}$

$\mathrm{b}=\rho_{c p}\left(T-T_{f_{i n}}\right) \geq 0$

$\mathrm{f}$ and $\mathrm{b}$ are systems uncertainties and external fluctuations. Even though, according to the SMC definition, the range of these parameters is specified, the limit of these parameters could be measured:

$$
\frac{\left|\dot{\mathrm{T}}_{\text {des }}-\mathrm{f}\right|}{\mathrm{b}}|\mathrm{e}(t)|<F
$$

$\mathrm{F}$ is always hard to measure for engineers, owing to the instability of system constraints. A trivial deviation from the system's high limit can cause a chattering phenomenon. The term chattering is associated with finite amplitude oscillations presenting in several sliding mode control applications. High-frequency switching of the controller is the main cause of this phenomenon [28].

For eliminating this seemingly possible problem, a compensating mass flow rate $(\mathrm{u})$ should be injected into the system circuit. As the system governed equation is as follows: $x^{n}=f+\mathrm{b} u$

According to the sliding surface definition:

$\mathrm{S}=\left(\frac{d}{d t}+\lambda\right)^{\mathrm{n}-1} \mathrm{e}(t)=\left(\frac{d}{d t}+\lambda\right)^{1-1} \mathrm{e}(t)=\mathrm{e}(t)$

The term $\lambda$ is a constant, and by considering $\dot{S}=0$ the equivalent control input $(\widehat{\mathrm{u}})$ is calculated as follows:

$\dot{S}=\dot{T}_{d e s}-\dot{T}=0$

$\left.\dot{T}_{\text {des }}-\hat{f}+\hat{u}\right)=0, \dot{T}_{\text {des }}=0$

$\hat{f}=-\hat{u}$

$\hat{\mathrm{f}}$ is the numerical mean value of the $\mathrm{f}$ and can be correlated as follows:

$|f \hat{f}| \leq F$

According to the SMC definition, the total control input can be evaluated:

$\mathrm{u}=\hat{\mathrm{b}}^{-1}[\hat{u}-k \operatorname{sign}(s)]$

Where $\hat{\mathrm{b}}$ and $\mathrm{k}$ can be examined as follow:

$\mathrm{k}=\beta(F+\eta)+(\beta-1)|\hat{u}|$

$\widehat{\mathrm{b}}=\left(\mathrm{b}_{\min } * \mathrm{~b}_{\max }\right)^{1 / 2}$

The value of $\beta$ is considered as follows [29]:

$\beta=\left(\frac{b_{\max }}{b_{\min }}\right)^{1 / 2}$

By substitution the mentioned parameters in the equation (18), the total control input is examined.

\subsection{Multi-objective optimization procedure}

The theory of multi-objective optimization is applied to obtain a standard configuration that joins all the objective functions. A multi-objective issue comprises optimizing (i.e., minimizing or maximizing) several objectives simultaneously, with inequality or equality constraints. Therefore, in this research, the performance of the considered cycle and the SMC system's response time is selected as goal functions. Therefore, in this article, there are various strategies for optimization:

A crucial step in formulating an optimization problem is the selection of independent decision variables that sufficiently characterize the possible design options. In this research, by including all significant variables that can affect the cost-effectiveness of the system, eliminating less significant variables, and distinguishing the amenable independent variables, decision variables have been presented in Table 2. The given constraints (limits) in Table 2 arise due to the limitations on the ranges of the physical variables and basic conservation principles, which must be satisfied.

Table 2. constraints of decision variables.

\begin{tabular}{|c|c|}
\hline Parameter & Constraint \\
\hline $\begin{array}{c}\text { The inlet pressure of HP turbine: } \\
\text { P1 (X1) }\end{array}$ & $80-170$ bar \\
P2 (X2) & $0.05-0.5$ bar \\
\hline $\begin{array}{c}\text { Outlet pressure of HP turbine: } \\
\text { TTD1 (X3) }\end{array}$ & $1-30^{\circ} \mathrm{C}$ \\
\hline $\begin{array}{c}\text { Feedwater heater-terminal temperature difference: } \\
\text { (X4) }\end{array}$ & $1-30^{\circ} \mathrm{C}$ \\
\hline $\begin{array}{c}\text { Superheater-terminal temperature difference: TTD } 2 \\
\text { (X5) }\end{array}$ & $1-30^{\circ} \mathrm{C}$ \\
\hline
\end{tabular}

The Multi-Objective Particle Swarm Optimization (MOPSO) approach as a robust optimization technique is employed for optimization. The optimization output provides a set of optimal configuration across the Pareto front, and all of these solutions can be taken as 
the optimal endpoint. The resolution of the overall optimal point depends on the decision-making policy. In the vast range of applications, the concept of an ideal unreachable spot (the spot with the most suitable values of the objective functions) is employed to determine the final optimum point. In this paper, the closest point from the Pareto front that is intimate to the ideal unreachable point is exposed as the final optimal point using the LINMAP method. The details regarding the optimization method and the adoption of final optimum points are displayed in [30].

\section{Results and Discussions}

\subsection{Validation}

To validate the proposed model in this article, an analogy between the results and the reference [31] is conducted and expressed in Table 3.

Table 3. The validation of the present model at 50MW capacity [26].

\begin{tabular}{|c|c|c|c|c|}
\hline Stream & Parameters & $\begin{array}{l}\text { Ref } \\
{[30]}\end{array}$ & Present & $\begin{array}{l}\text { Error } \\
(\%)\end{array}$ \\
\hline Inlet to HP turbine & $\begin{array}{l}\text { Temperature }\left({ }^{\circ} \mathrm{C}\right) \\
\text { Pressure (bar) } \\
\text { Mass flow rate } \\
(\mathrm{Kg} / \mathrm{s})\end{array}$ & $\begin{array}{l}371 \\
100 \\
57.55\end{array}$ & $\begin{array}{l}371 \\
100 \\
55.81\end{array}$ & $\begin{array}{l}0 \\
0 \\
3.02\end{array}$ \\
\hline Inlet to LP turbine & $\begin{array}{l}\text { Temperature }\left({ }^{\circ} \mathrm{C}\right) \\
\text { Pressure (bar) } \\
\text { Mass flow rate } \\
(\mathrm{Kg} / \mathrm{s})\end{array}$ & $\begin{array}{l}370 \\
16.5 \\
46.01\end{array}$ & $\begin{array}{l}370 \\
16.5 \\
44.6\end{array}$ & $\begin{array}{l}0 \\
0 \\
3.06\end{array}$ \\
\hline $\begin{array}{l}\text { Outlet from LP } \\
\text { turbine }\end{array}$ & $\begin{array}{l}\text { Temperature }\left({ }^{\circ} \mathrm{C}\right) \\
\text { Pressure (bar) } \\
\text { Mass flow rate } \\
(\mathrm{Kg} / \mathrm{s})\end{array}$ & $\begin{array}{l}45.01 \\
0.096 \\
38.35\end{array}$ & $\begin{array}{l}45.01 \\
0.096 \\
36.9\end{array}$ & $\begin{array}{l}0 \\
0 \\
3.78\end{array}$ \\
\hline $\begin{array}{l}\text { Inlet HTF to } \\
\text { power block }\end{array}$ & $\begin{array}{l}\text { Temperature }\left({ }^{\circ} \mathrm{C}\right) \\
\text { Pressure (bar) } \\
\text { Mass flow rate } \\
(\mathrm{Kg} / \mathrm{s})\end{array}$ & $\begin{array}{l}393 \\
20 \\
567.1\end{array}$ & $\begin{array}{l}393 \\
2 \\
550\end{array}$ & $\begin{array}{l}0 \\
5.00 \\
3.02\end{array}$ \\
\hline $\begin{array}{l}\text { Outlet HTF to } \\
\text { power block }\end{array}$ & $\begin{array}{l}\text { Temperature }\left({ }^{\circ} \mathrm{C}\right) \\
\text { Pressure (bar) } \\
\text { Mass flow } \\
\text { rate }(\mathrm{Kg} / \mathrm{s})\end{array}$ & $\begin{array}{l}296 \\
15 \\
567.1\end{array}$ & $\begin{array}{l}295 \\
15 \\
550\end{array}$ & $\begin{array}{l}0.34 \\
0 \\
3.02\end{array}$ \\
\hline $\begin{array}{l}\text { Thermal efficiency } \\
\text { of the power block }\end{array}$ & & 37.26 & 36.81 & $\begin{array}{l}0.45 \\
(\mathrm{abs})\end{array}$ \\
\hline $\begin{array}{l}\text { Exergetic } \\
\text { efficiency of the } \\
\text { power block }\end{array}$ & & 62.64 & 66.66 & $\begin{array}{l}4.22 \\
(\mathrm{abs})\end{array}$ \\
\hline NET power $(M W)$ & & 50 & 49.50 & 0.40 \\
\hline
\end{tabular}

The consequences of the simulations and optimizations on the solar thermal power plant are presented in this section. The effects of operational and thermodynamic variables on the output power, exergetic efficiency, and exergy destruction rate of the power plant are presented in Figures 3-8. Figure 3 shows the impact of the Superheater terminal temperature difference (TTD) on the cycle performance. It is revealed that with the increase in the terminal temperature difference in the superheater, the quantity of exergy degradation is increased $(2 \%)$, and the total output power and exergetic efficiency are reduced $(\sim 1.2 \%)$. Also, by increasing the value of this parameter, the minimum temperature difference between the superheater's cold inlet and the superheater's hot outlet increases, diminishing the superheater output temperature and, consequently, the superheater's hot outlet, decreases the inlet steam temperature entering the turbine. As a result, the amount of power and exergetic efficiency of the cycle is lessened, and the rate of exergy destruction of the cycle goes up.

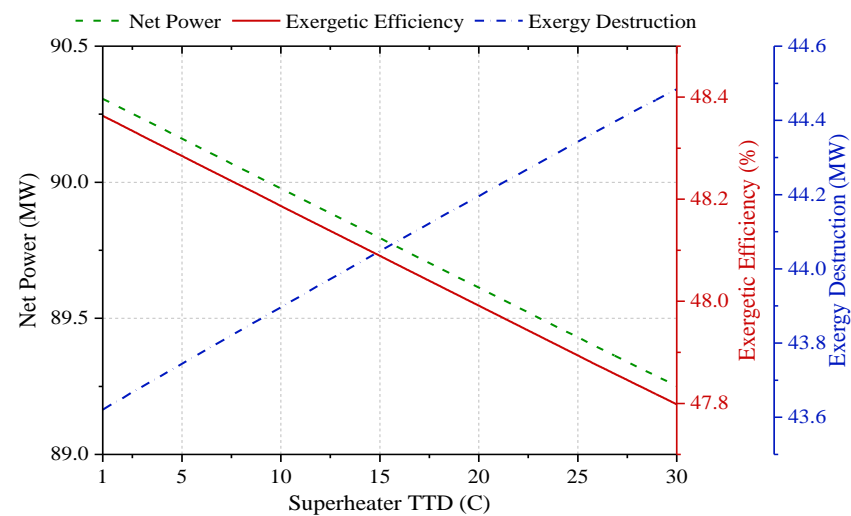

Figure 3. The impact of superheater terminal temperature difference on exergetic efficiency, exergy destruction, and net power.

The effects of turbine pressure on the net power, exergetic efficiency, and exergy destruction rates of the power plant are shown in Figure 4. In Figure 4(a), at lower pressures, by increasing the turbine inlet pressure, the exergy destruction rate decreases, and both the system's exergetic efficiency and power output are increased. A higher rate of irreversibilities has occurred when the turbine inlet pressure increases to a higher rate. As a result, a less efficient operation of the cycle has appeared.

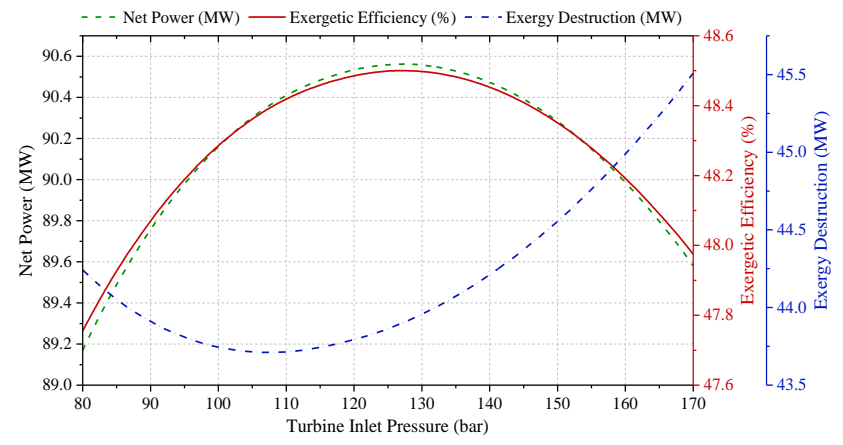

Figure 4. (a) The impact of turbine inlet pressure on net power, exergy efficiency, and exergy destruction.

According to Figure 4(b), by increasing the turbine outlet pressure (which means increasing the condenser pressure), the value of the turbine pressure ratio decreases, which adversely affects the cycle's power productivity and, thus, its fuel-to-power efficiency. Naturally, less power production of the cycle in this way means wasting the exergy of the steam flow through the turbine to the condenser, and consequently, a higher rate of exergy destruction (29\%). 


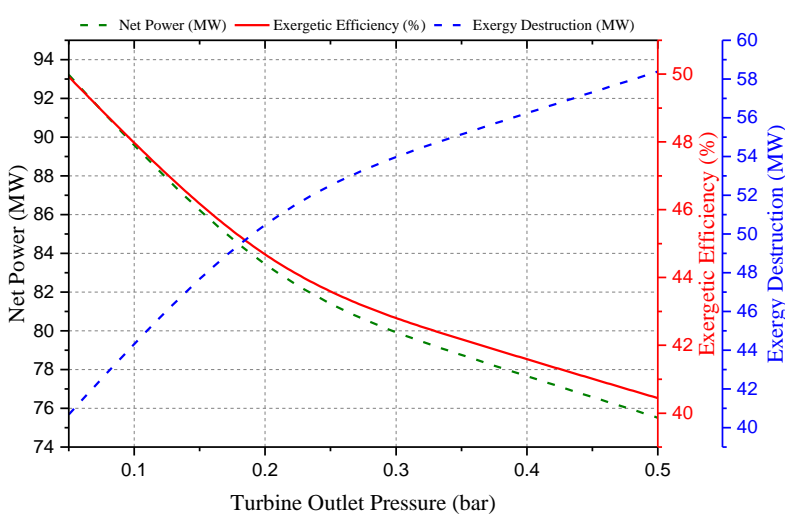

Figure 4. (b) The effect of turbine outlet pressure on net power, exergy efficiency, and exergy destruction.

In Figure 5, the effects of changes in the solar system's outlet temperature on the whole cycle's performance are illustrated. The solar cycle's output temperature is directly associated with the steam temperature. This parameter is expected to be followed by a continuous increase in the cycle's efficiency and a decrease in the exergy destruction term.. However, what is seen is that, due to the increase in the collector's outlet temperature from $330^{\circ} \mathrm{C}$ to about $350^{\circ} \mathrm{C}$, the exergetic efficiency $(48 \%)$ and output power rapidly increase $(67 \%)$, and therefore, further growth of this temperature leads to smoother growth of these two parameters. On the other hand, a higher collectors' outlet temperature causes higher exergy destructions rates, up to $350^{\circ} \mathrm{C}$.

Meanwhile, further increase coincides with improving the rates of irreversibility slightly. The peak irreversibility rate was observed at the critical collectors' outlet temperature of $345^{\circ} \mathrm{C}$ where it hits the peak value of $47 \mathrm{MW}$. The exergetic efficiency and power production rate at this point are $45 \%$ and $84 \mathrm{MW}$, respectively.

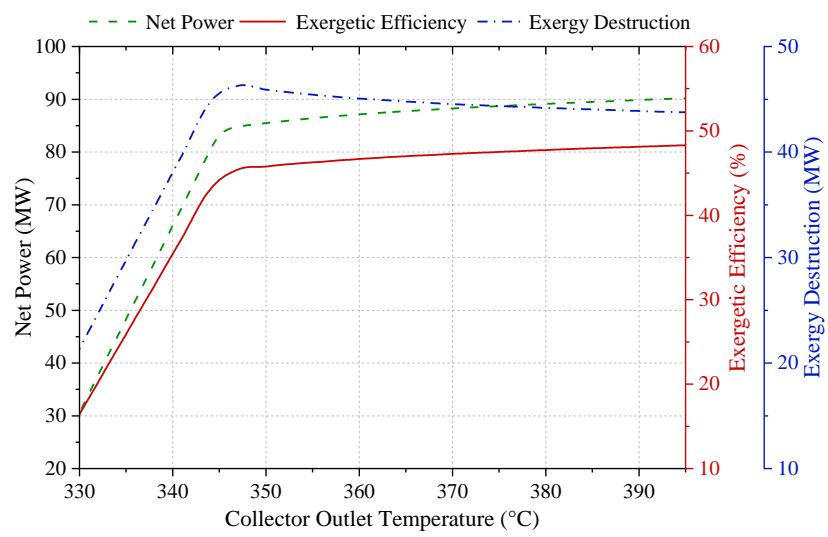

Figure 5. The impact of collector outlet temperature on net output power, exergetic efficiency, and exergy destruction.

Figure 6 shows the effect of the average solar radiation intensity on the performance of the cycle. As seen in the figure, and well-expectedly, increasing the DNI level improves the collectors' heat output and thereby increases the amount of output power and the exergetic efficiency of the cycle. On the other hand, the higher the DNI value, the larger the power plant's rate of exergy degradation will occur. For example, at a DNI of $500 \mathrm{~W} / \mathrm{m}^{2}$, the exergetic efficiency, the power output, and irreversibility rates are $42 \%, 50 \mathrm{MW}$ and $44 \mathrm{MW}$, while these parameters will reach the higher points of 47\%, $95 \mathrm{MW}$ and $47 \mathrm{MW}$ at DNI $=700 \mathrm{~W} / \mathrm{m}^{2}$.

Figure 7 reveals the effect of ambient temperature changes on the cycle performance. According to the figure, as the ambient temperature increases, the amount of heat received from the collector field increases, resulting in a sharp increase of solar working fluid mass flow rate, resulting in a growth in the supercritical output temperature and the turbine inlet temperature. The accumulated effect of these changes is an increase in the cycle's power (47\%) and exergy efficiency $(15 \%)$ and a linear rise of the irreversibility rate $(2.5 \%)$.

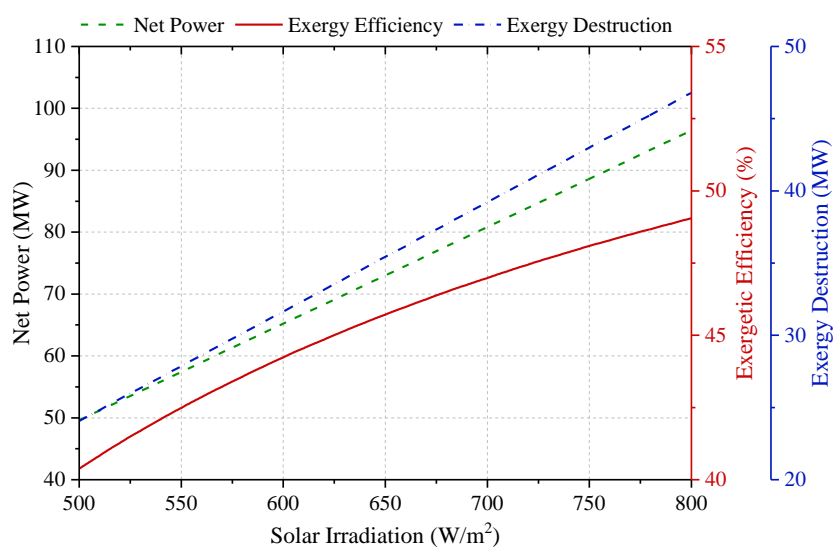

Figure 6. The impact of collector outlet temperature on net output power, exergy efficiency, and exergy destruction.

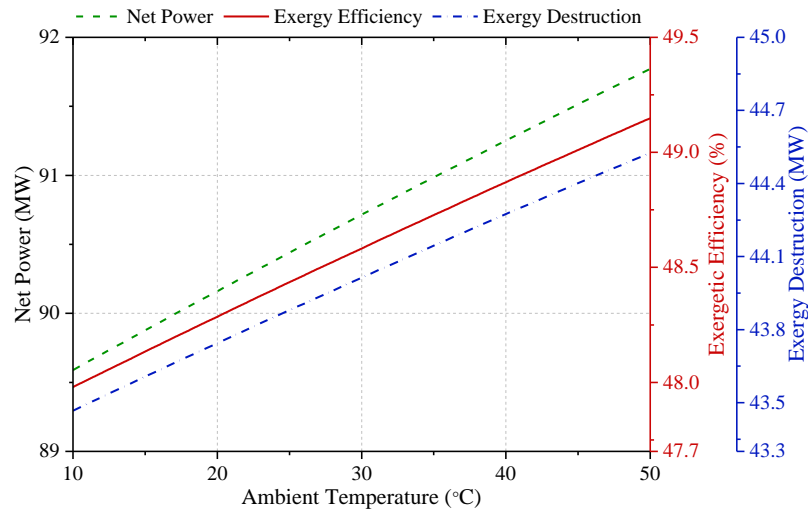

Figure 7. The impact of ambient temperature on net output power, exergy efficiency, and exergy destruction.

The objective of control system development was to maintain the solar collector system temperature at a fixed level. For this purpose, a robust non-linear control approach has been utilized. This control technique tries to overcome immediate uncertainties and external fluctuations that may cause systems to misfunction by injecting compensating mass flow rate to the solar field circuit. As shown in Figure 8 , the control technique met the control demand after 4 hours of simulation. It should be noted that the reference signal for the system was $395^{\circ} \mathrm{C}$.

Moreover, the sliding surface figure Figure 9, which is defined as determining the system's error, shows a trivial error. The error defines the difference between system output temperature and a reference signal. 


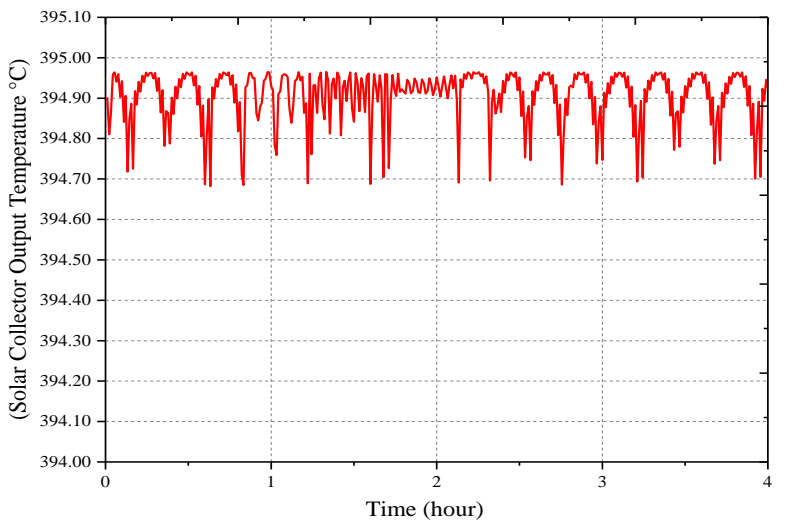

Figure 8. Solar tracking system outcome.

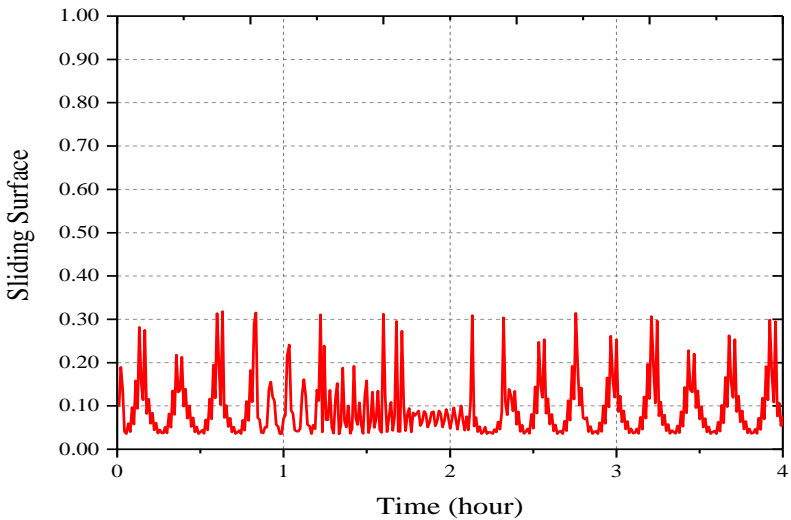

Figure 9. System state alternation on the sliding surface.

The injecting flow rate for compensating energy variations in the solar system circuit is plotted in Figure 10. Furthermore, this figure illustrates the HTF flow rate during the simulation.

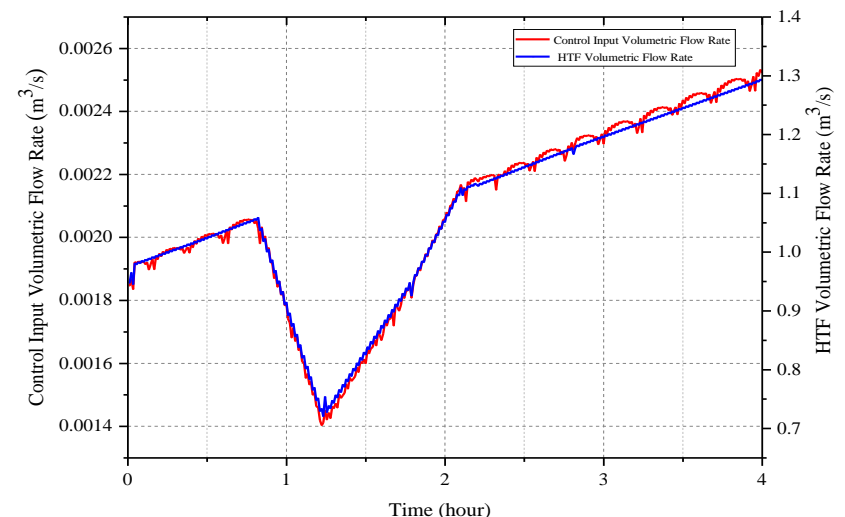

Figure 10. Comparison between control input and solar cycle HTF volumetric flow rate.

Based on two and three-criteria optimization to maximize exergetic-energy efficiency and minimize the control system's response time, the optimization Pareto front is created and shown in Figure 11 (in two realistic and normalized states). Figure 12(a) represents how thermodynamic parameters and response time vary during the simulation. This is clarified with a two-dimensional contour in Figure 12(a). As the objective functions have different units, the comparison of their variations might be challenging in Figure 12(a). Therefore, for a better understanding, a normalized two-dimensional contour has been presented in Figure 12 (b).

The ideal unreachable point has been evaluated in both Pareto fronts.
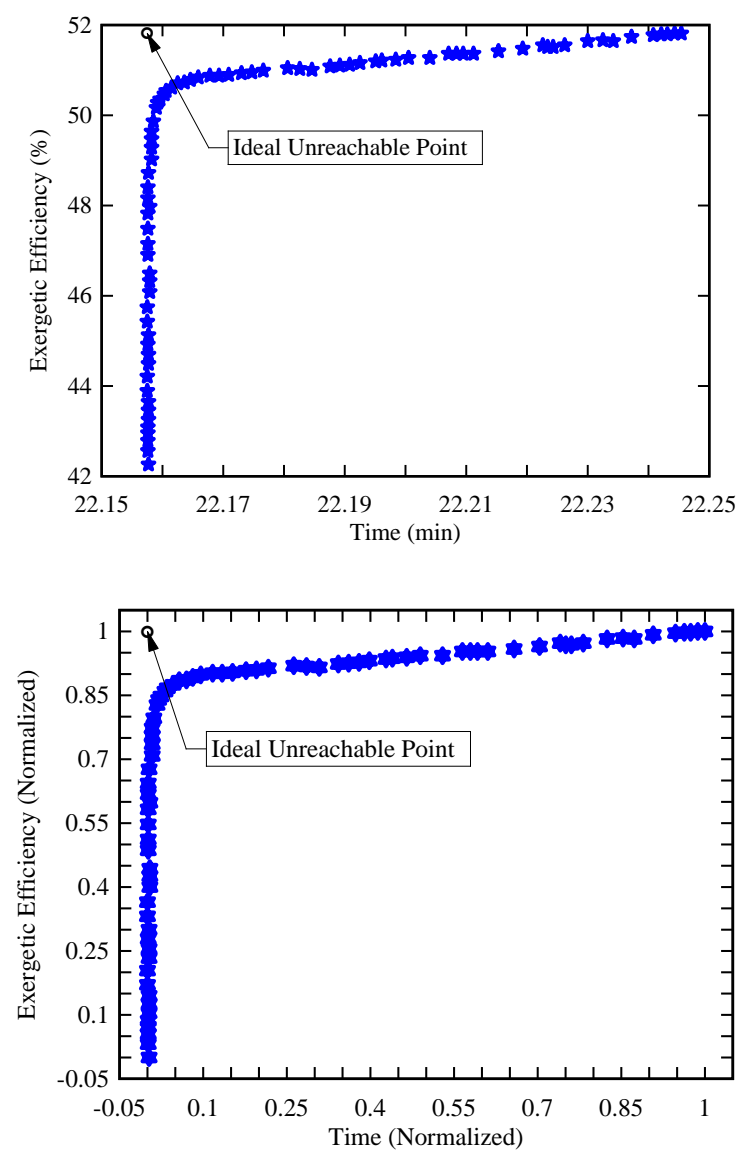

Figure 11. The actual and normalized Pareto front for twoobjective optimization.

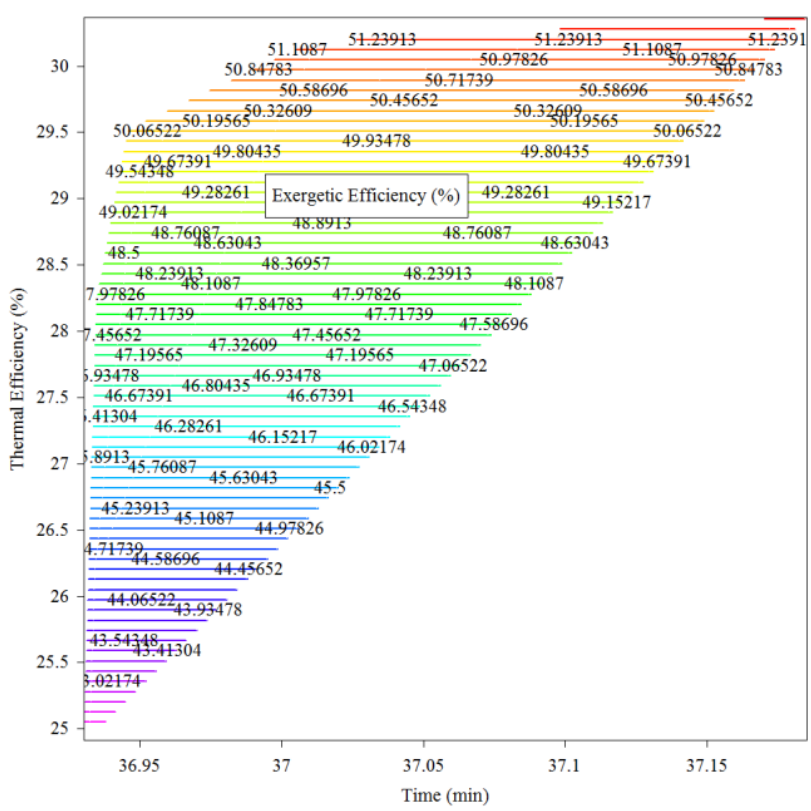

Figure 12. a) The actual Pareto front for three-objective optimization. 


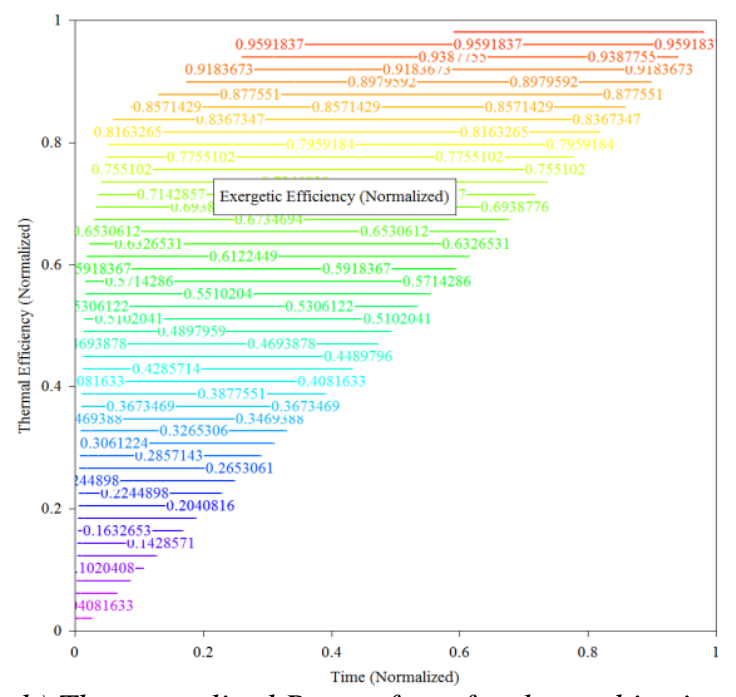

b) The normalized Pareto front for three-objective optimization.
The results of multi-objective optimization and required comparison are shown in Table 4. As the Table shows, in the two-objective optimization (response time and exergy), the objective functions improved about 22.01 and $5.46 \%$, respectively. Although there is a $3.68 \%$ and $3.74 \%$ improvement in the energy and exergetic efficiencies in the three objective optimization, the control system response time is increased about $30 \%$. This may have downside effects on the power plant's performance and cause a massive mass flow rate in the solar unit. The solar unit operating cost is extravagant itself in the present century. Thus, the priority should be lessening the unnecessary mass flow rate when the price of the thermal oil (HTF) using in solar units is high. Therefore, the two-objective optimization scheme is the preferred scheme, even though it has a lesser improvement of the energy and exergy efficiencies than the three-objective optimization process.

Table 4. The comparison of the final optimum point in two and three objective optimizations with the base case.

\begin{tabular}{|c|c|c|c|c|c|c|c|c|c|c|c|}
\hline & \multicolumn{5}{|c|}{ Optimum Variables } & \multicolumn{6}{|c|}{ Goal Function } \\
\hline & \multirow[b]{2}{*}{$P 1$} & \multirow[b]{2}{*}{$P 2$} & \multirow[b]{2}{*}{ TTD1 } & \multirow[b]{2}{*}{ TTD2 } & \multirow[b]{2}{*}{ TTD3 } & \multicolumn{2}{|r|}{ time } & \multicolumn{2}{|c|}{ Thermal efficiency } & \multicolumn{2}{|c|}{ Exergetic Efficiency } \\
\hline & & & & & & Value & Improvement & Value & Improvement & Value & Improvement \\
\hline Base Design & 100 & 0.08 & 5 & 5 & 5 & 28.416 & -.- & 28.46 & --. & 48.28 & --- \\
\hline $\begin{array}{l}\text { two-Objective } \\
\text { optimization }\end{array}$ & 81.04 & 0.05 & 6.30 & 11.62 & 6.97 & 22.16 & $22.01 \%$ & $\underline{29.06^{a}}$ & $2.10 \%$ & 50.92 & $5.46 \%$ \\
\hline $\begin{array}{l}\text { three-Objective } \\
\text { optimization }\end{array}$ & 84.80 & 0.06 & 20.68 & 25.92 & 7.93 & 36.94 & $-30.02 \%$ & 29.52 & $3.68 \%$ & 50.09 & $3.74 \%$ \\
\hline
\end{tabular}

${ }^{\text {a }}$ calculated by the user.

\section{Conclusion}

The chief objective of this paper is to determine an optimal thermodynamic-control configuration for a Rankinecycle based parabolic trough solar power plant. For this goal, exergy and energy analyses were used to evaluate the proposed cycle's thermodynamic performances. The nonlinear SMC is used for dynamic analysis and temperature tracking to achieve the reference temperature accurately as possible. Moreover, the results of sensitivity analysis of input parameters show that by increasing environmental parameters such as DNI and ambient temperature, output power and exergy efficiency are significantly increased. Conversely, changes in power plant operating parameters such as, turbine outlet pressure and minimum superheater temperature affect output power and exergy efficiency, increase exergy destruction and decrease output power and exergetic efficiency. Subsequently, multi-objective optimization is performed utilizing the MOPSO tool to obtain an overall optimal configuration with a favorable quantity for objective functions. The optimization outcomes illustrate that two-objective optimization with an improvement of about 22.2 , and $5 \%$ in response time of the control system and energy/exergy efficiencies can provide a marked improvement in the proposed system.

\section{Nomenclature}

$$
\text { A } \quad \text { area, }\left(\mathrm{m}^{2}\right)
$$

argument continuous vector

heat capacity $(\mathrm{kj} / \mathrm{kg})$

Concentrated solar power plant

pipe diameter

exergy, (kj)

system error

system uncertainty upper value argument continuous vector aperture area, $\left(\mathrm{m}^{2}\right)$ specific enthalpy, (kj/kg) global Thermal loss

Heat transfer fluid

direct solar irradiance

Process gain

length of each row of collector absorber, the total length of the collectors mass $(\mathrm{kg})$ multi-objective particle swarm number organic rankine cycle phase change material parabolic through collector heat transfer per unit mass $(\mathrm{kj} / \mathrm{kg})$ heat transfer coefficient $\mathrm{W} /\left(\mathrm{m}^{2} \mathrm{~K}\right)$ sliding surface entropy Sliding mode control 


$\begin{array}{ll}\mathrm{T} & \text { temperature, }(\mathrm{K}) \\ \mathrm{u} & \text { control input } \\ \mathrm{V} & \text { Lyapunov function } \\ \mathrm{W} & \text { specific work output, (kj/kg) } \\ \mathrm{W} & \text { width of the collector, }(\mathrm{m}) \\ \mathrm{X} & \text { system trajectory } \\ \mathrm{y} & \text { mole fraction } \\ \eta_{\mathrm{mT}} & \text { turbine mechanical efficiency } \\ \eta_{\mathrm{mP}} & \text { pump mechanical efficiency } \\ \rho & \text { density } \\ \rho_{\mathrm{cp}} & \text { temperature function } \\ \phi & \text { rim angle } \\ \mu & \text { Chemical exergy } \\ \lambda & \text { Positive constant } \\ \mathrm{Subscripts} & \\ \mathrm{a} & \text { ambient } \\ \mathrm{b} & \text { beam } \\ \mathrm{c} & \text { collector } \\ \mathrm{D} & \text { destruction } \\ \mathrm{e} & \text { electrical } \\ \mathrm{f} & \text { fluid } \\ \mathrm{g} & \text { global } \\ \mathrm{ge} & \text { generator } \\ \mathrm{i} & \text { input } \\ \text { tot } & \text { total } \\ \mathrm{m} & \text { metal } \\ \mathrm{o} & \text { output } \\ \mathrm{P} & \text { pump } \\ \mathrm{r} & \text { reference } \\ \mathrm{T} & \text { turbine } \\ \mathrm{t} & \text { time } \\ \text { tot } & \text { total } \\ \text { in } & \text { inlet } \\ \mathrm{ps} & \text { parallel segment } \\ \mathrm{des} & \text { desired } \\ & \end{array}$

\section{References:}

[1] A. Arabkoohsar and G. B. B. Andresen, "Design and analysis of the novel concept of high temperature heat and power storage," Energy, vol. 126, pp. 2133, 2017, doi: 10.1016/j.energy.2017.03.001.

[2] M. Balghouthi, S. E. Trabelsi, M. Ben Amara, A. B. H. Ali, and A. Guizani, "Potential of concentrating solar power (CSP) technology in Tunisia and the possibility of interconnection with Europe," Renew. Sustain. Energy Rev., vol. 56, pp. 1227-1248, 2016 , doi: https://doi.org/10.1016/j.rser.2015.12.052.

[3] J. Sachdeva and O. Singh, "Thermodynamic analysis of solar powered triple combined Brayton, Rankine and organic Rankine cycle for carbon free power," Renew. Energy, vol. 139, pp. 765-780, 2019.

[4] J. Yang, J. Li, Z. Yang, and Y. Duan, "Thermodynamic analysis and optimization of a solar organic Rankine cycle operating with stable output," Energy Convers. Manag., vol. 187, pp. 459$471,2019$.

[5] H. Ishaq and I. Dincer, "Analysis and optimization for energy, cost and carbon emission of a solar driven steam-autothermal hybrid methane reforming for hydrogen, ammonia and power production," $J$. Clean. Prod., vol. 234, pp. 242-257, 2019.
[6] H. Zhang, Y. Liu, X. Liu, and C. Duan, "Energy and exergy analysis of a new cogeneration system based on an organic Rankine cycle and absorption heat pump in the coal-fired power plant," Energy Convers. Manag., vol. 223, p. 113293, 2020.

S. Adibhatla and S. C. Kaushik, "Exergy and thermoeconomic analyses of 500 MWe sub critical thermal power plant with solar aided feed water heating," Appl. Therm. Eng., vol. 123, pp. 340-352, 2017.

[8] C. Xu et al., "A thermodynamic analysis of a solar hybrid coal-based direct-fired supercritical carbon dioxide power cycle," Energy Convers. Manag., vol. 196, pp. 77-91, 2019.

[9] E. G. Cojocaru, J. M. Bravo, M. J. Vasallo, and D. M. Santos, "Optimal scheduling in concentrating solar power plants oriented to low generation cycling," Renew. Energy, vol. 135, pp. 789-799, 2019.

[10] K. Rashid, S. M. Safdarnejad, K. Ellingwood, and K. M. Powell, "Techno-economic evaluation of different hybridization schemes for a solar thermal/gas power plant," Energy, vol. 181, pp. 91106, 2019, doi: https://doi.org/10.1016/j.energy.2019.05.130.

[11] S. Khajepour and M. Ameri, "Techno-economic analysis of using three Fresnel solar fields coupled to a thermal power plant for different cost of natural gas," Renew. Energy, vol. 146, pp. 2243-2254, 2020.

[12] E. Tapaches, D. Salas, M. Perier-Muzet, S. Mauran, D. Aussel, and N. Mazet, "The value of thermochemical storage for concentrated solar power plants: economic and technical conditions of power plants profitability on spot markets," Energy Convers. Manag., vol. 198, p. 111078, 2019.

[13] M. Babaelahi, E. Mofidipour, and E. Rafat, "Design, dynamic analysis and control-based exergetic optimization for solar-driven Kalina power plant," Energy, vol. 187, p. 115977, 2019.

[14] T. Sung, S. Y. Yoon, and K. C. Kim, "A mathematical model of hourly solar radiation in varying weather conditions for a dynamic simulation of the solar organic rankine cycle," energies, vol. 8, no. 7, pp. 7058-7069, 2015.

[15] W. A. K. Al-Maliki, F. Alobaid, V. Kez, and B. Epple, "Modelling and dynamic simulation of a parabolic trough power plant," J. Process Control, vol. 39, pp. 123-138, 2016, doi: https://doi.org/10.1016/j.jprocont.2016.01.002.

[16] K. Rashid, K. Mohammadi, and K. Powell, "Dynamic simulation and techno-economic analysis of a concentrated solar power (CSP) plant hybridized with both thermal energy storage and natural gas," $J$. Clean. Prod., vol. 248, p. 119193, 2020.

[17] F. Calise, M. D. d'Accadia, L. Libertini, and M. Vicidomini, "Thermoeconomic analysis of an integrated solar combined cycle power plant," Energy Convers. Manag., vol. 171, pp. 1038-1051, 
2018.

[18] X. Li, E. Xu, L. Ma, S. Song, and L. Xu, "Modeling and dynamic simulation of a steam generation system for a parabolic trough solar power plant," Renew. Energy, vol. 132, pp. 998-1017, 2019.

[19] N. Abas, A. R. Kalair, M. Seyedmahmoudian, M. Naqvi, P. E. Campana, and N. Khan, "Dynamic simulation of solar water heating system using supercritical $\mathrm{CO} 2$ as mediating fluid under sub-zero temperature conditions," Appl. Therm. Eng., vol. 161, p. 114152, 2019.

[20] A. J. Gallego, G. M. Merello, M. Berenguel, and E. F. Camacho, "Gain-scheduling model predictive control of a Fresnel collector field," Control Eng. Pract., vol. 82, pp. 1-13, 2019.

[21] M. V. A. da Costa, A. Narasimhan, D. Guillen, B. Joseph, and D. Y. Goswami, "Generalized distributed state space model of a CSP plant for simulation and control applications: Single-phase flow validation," Renew. Energy, vol. 153, pp. 3648, 2020.

[22] Z. Tian, J. Yuan, X. Zhang, L. Kong, and J. Wang, "Modeling and sliding mode predictive control of the ultra-supercritical boiler-turbine system with uncertainties and input constraints," ISA Trans., vol. 76, pp. 43-56, 2018.

[23] H. J. Mosleh and R. Ahmadi, "Linear parabolic trough solar power plant assisted with latent thermal energy storage system: A dynamic simulation," Appl. Therm. Eng., vol. 161, p. 114204, 2019.

[24] X. Chen, C. Liu, Q. Li, X. Wang, and X. Xu, "Dynamic analysis and control strategies of Organic Rankine Cycle system for waste heat recovery using zeotropic mixture as working fluid," Energy Convers. Manag., vol. 192, pp. 321-334, 2019.

[25] E. Mofidipour and M. Babaelahi, "New procedure in solar system dynamic simulation, thermodynamic analysis, and multi-objective optimization of a postcombustion carbon dioxide capture coal-fired power plant," Energy Convers. Manag., vol. 224, 2020, doi: 10.1016/j.enconman.2020.113321.

[26] M. Babaelahi, E. Mofidipour, and E. Rafat, "Combined Energy-Exergy-Control (CEEC) analysis and multi-objective optimization of parabolic trough solar collector powered steam power plant," Energy, vol. 201, 2020, doi: 10.1016/j.energy.2020.117641.

[27] Sidibba, Ahmed, Diene Ndiaye, Diouma Kobor, Menny El Bah, and Sidi Bouhamady. "Energy and exergy analysis of a solar photovoltaic module performance under the Sahelian Environment." International Journal of Physical Sciences 13, no. 12 (2018): 196-205.

[28] J.-J. E. Slotine and W. Li, Applied nonlinear control, vol. 199, no. 1. Prentice hall Englewood Cliffs, NJ, 1991.

[29] R. Carmona, "Analysis, modeling and control of a distributed solar collector field with a one-axis tracking system," Spanish Univ. Seville, Spain, 1985.

[30] K. K. Mandal, M. Basu, and N. Chakraborty, "Particle swarm optimization technique based shortterm hydrothermal scheduling," Appl. Soft Comput., vol. 8, no. 4, pp. 1392-1399, 2008.

[31] T. E. Boukelia, M. S. Mecibah, B. N. Kumar, and K. S. Reddy, "Investigation of solar parabolic trough power plants with and without integrated TES (thermal energy storage) and FBS (fuel backup system) using thermic oil and solar salt," Energy, vol. 88, pp. 292-303, 2015. 